\title{
Dielectrical and electrical properties of PVA-NaI composites
}

\section{Hussein Neama Najeeb, Ghaleb Abdul Wahab, Ahmed Kadem Kodeary, Ahmed Baqer, Rafia Tiema Ahmed}

Department of Physics, Collage of Science for Women, Babylon University

E-mail: Neama.hussein@yahoo.com

\begin{abstract}
The electrical characteristics of polyvinyl alcohol PVA doped with different concentrations $(0,1,2,3$ and $4 \mathrm{wt} \%)$ of sodium iodide NaI powder were studied. The films are prepared using solution casting technique, in order to investigate the effect of sodium iodide NaI additions on the electrical properties of PVA host. The D.C conductivity measured by measuring the D.C electrical resistance using the Keithly Electrometer type 616C, and for different temperatures ranging from $30-70^{\circ} \mathrm{C}$.

The dielectric properties measured by measuring the capacitor and the loss angle tangent as a function of the alternating electric field frequency using the Agilent impedance analyzer 4294A, within the frequency range $50-6 \times 10^{6} \mathrm{~Hz}$ at room temperature. The experimental results showed that the dielectric constant is decrease with increase frequency of applied electrical field and increase with increasing concentrations, dielectric loss is increase with increasing frequency of applied electrical field to be $1 \mathrm{MHz}$ after this it was decreasing, A.C electrical conductivity are increasing with increasing frequency of applied electrical field, also, the results showed that the D.C electrical conductivity are increasing with increase concentration of $\mathrm{NaI}$ and temperature, activation energy are decreasing with increase concentration of additive salt.
\end{abstract}

Key words

Polymer, composites, electrical properties.

Article info.

Received: Sep. 2012

Accepted: Apr. 2013

Published: Dec. 2013

\section{PVA-NaIالخصائص العزليه والكهربائية لمتر اكبات \\ حسين نعمه نجيب، غالب عبد الوهاب الدهش، احمد كاظم خضيري، احمد باقر رضا، رافع طعمه احمد قسم الفيزياء، كلية العلوم لللبنات، جامعة بابل}

تم دراسة الخصائص الكهربائية لبوليمر بولي فنيل الكحول وبنسب وزنيه مختلفة من يوديد الصوديوم (4,3,2,1,0wt\%).

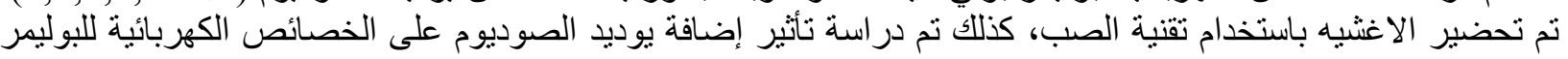

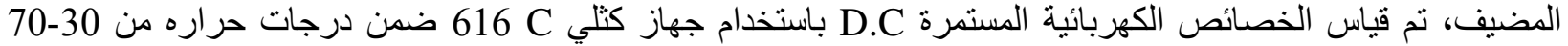
درجه مئوية. قيست الخصائص العز ليه بقياس السعه وظل زاوية الفقد كداله لتردد المجال المسلط ضمن مدى تردد

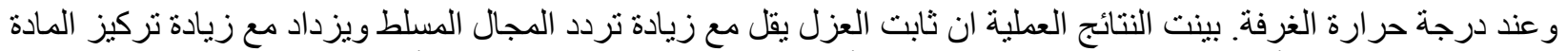

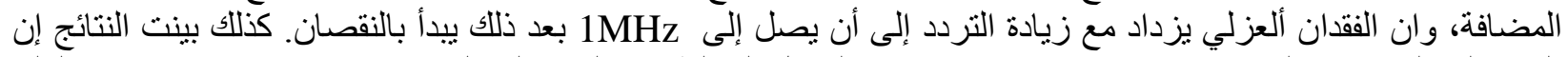

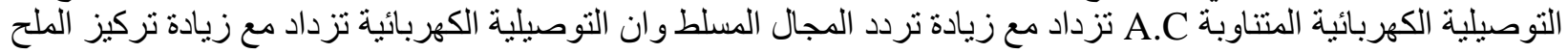

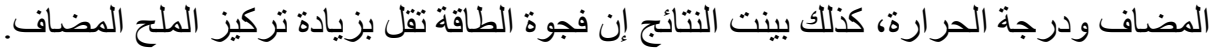




\section{Introduction}

Electrical conduction in polymers has been extensively studied in recent years to understand the nature of charge transport in these materials. Various conduction mechanisms such as Schottky effect, the pool-frenkel effect, space charge limited conduction and hopping conduction have been suggested for the charge transport [1].

Many polymers have excellent electrical properties, as well as a variety of physical, chemical, and mechanical properties, that make them very suitable for insulating materials[2]. Since knowledge of the nature of electrical conduction in insulating materials is incomplete [2]. The conducting polymers also known as conductive plastics are being developed for many uses such as corrosion inhibitors, compact capacitors, antistatic coating, electromagnetic shielding and smart windows; which capable to vary the amount of light to pass[3,4]. Electrical conductivity measurement is one of the most convenient tools in studying Such structural changes of powder compacts, and has the advantage that the conductivity can de measured continuously throughout the whole densification process [5].

When applying electrical field on a capacitor terminals consisting of an electrical insulator between its plates, local displacement for the centers of positive and negative charges takes place, induced electrical dipole moments are generating, resulting in an electrical polarity process [6]; its value equals to the sum of moments of all dipoles existed in the sample unit volume [7]:

Polarization of substances can be identified by the constituents of this polarization so that the total polarization [8]:

$$
P=P_{e}+P_{i}+P_{d}+P_{o}
$$

Electronic Polarization $\left(\mathbf{P}_{\mathbf{e}}\right)$ : it occurs due to distortion in the distribution of the charge as a result of an external electrical field. A separation occurs between the nucleus positive charge and the center of the negative charge, which results in generating induced dipoles; this takes place in a very short time $\left(10^{-15}\right.$ seconds) and is independent on temperature.

Ionic Polarization $\left(\boldsymbol{P}_{\boldsymbol{i}}\right)$ : it was formed in an ionic compound having ionic characteristics. It takes place when the matter is under an electric field which changes the ionic bond lengths, resulting in the generation of a net dipole moment that has not been existed in the molecule before. It lasts for a short time $\left(10^{-11}-10^{-13}\right.$ second $)$. This type of polarization is independent on temperature.

\section{Rotational or Orientation Polarization} $\left(\mathbf{P}_{\mathbf{d}}\right)$ : it happens in molecules that have permanent dipole moment. On applying an electric field, the dipoles revolve around the axis and arrange themselves in the field direction. This type of polarization depends on temperature, and takes a considerable time to occur.

\section{Space Charge or Interfacial Polarization} $\left(\boldsymbol{P}_{\mathbf{0}}\right)$ : it takes place when a matter contains impurities, vacuum, or structural flaw, resulting in the concentration of opposite charge on the terminals of the impurity; this means the generating of dipoles in the atom, molecule, or region of the matter. This type of polarization depends on the homogeneity of the matter and the rate of being free from impurities. It mostly takes place in radio waves and can extend to below audio frequencies, depending on the flaw that causes the polarization

\section{Experimental Part Materials and Utilized Equations}

polyvinyl alcohol PVA doped with sodium iodide $\mathrm{NaI}$ was prepared with weight percentage $(0,1,2,3$ and $4 \mathrm{wt} \%)$ it was 
dissolved in glass beaker $(30 \mathrm{ml})$ by water using magnetic stirrer and placed in Petri dish ${ }^{\circ} \mathrm{cm}$ diameter using casting technique to prepare the films .Each sample was poured in $25 \mathrm{~cm}^{2}$ glass basin after being cleaned with water using ultrasonic device. The samples were put in dried oven at $50{ }^{\circ} \mathrm{C}$ for $2 \mathrm{~h}$.The thicknesses of the dried samples are 0.03 to $0.07 \mathrm{~cm}$.

The electronic balanced of accuracy $10^{-4}$ have been used to obtain a weight amount of NaI powder and polymer powder.

The dielectric properties of PVA- NaI composites were measured using (Agilent impedance analyzer 4294A), in the frequency(f) range $50-6 \times 10^{6} \mathrm{~Hz}$ at room temperature. The D.C electrical resistance using the Keithly Electrometer type 616C, and for different temperatures ranging from $30-70^{\circ} \mathrm{C}$.

The dielectric constant $(\dot{\varepsilon})$, is calculated by using the following expression:

$$
\varepsilon^{\prime}=\frac{\mathrm{Cd}}{\varepsilon_{\circ} \mathrm{A}}
$$

where $\mathrm{d}$ is the thickness of the films and A is surface area of the films

The dielectric loss $\varepsilon^{\prime \prime}$ is calculated by using the following equation

$\varepsilon^{\prime \prime}=\dot{\varepsilon} \times \tan \delta$

where $\tan \delta$ is dissipation factor .

The A.C conductivity ( $\sigma_{\mathrm{ac}}$ ) is calculated by the following equation:

$\sigma_{\mathrm{ac}}=\varepsilon_{\circ} \omega \varepsilon^{\prime \prime}$

where $\varepsilon_{0}$ is the permittivity of free space and $\omega$ is the angular frequency. The volume electrical conductivity $\sigma_{v}$ defined by :

$\sigma_{v}=\frac{1}{\rho_{v}}=\frac{L}{R A}$

where

$\mathrm{A}=$ guard electrode effective area.

$\mathrm{R}=$ volume resistance $(\mathrm{Ohm})$.

$\mathrm{L}=$ average thickness of sample $(\mathrm{cm})$.
In this model the electrodes have circular area $\mathrm{A}=\pi \mathrm{D}^{2} / 4$ where $\mathrm{D}=2.5 \mathrm{~cm}^{2}$.

The activation energy was calculated by using the following equation:

$\sigma=\sigma_{0} \operatorname{EXP}\left(-E_{a c t} / K T\right)$

where $\sigma$ is electrical conductivity at $\mathrm{T}$ temperature, $\sigma_{\mathrm{o}}$ is electrical conductivity at absolute zero of temperature, $\mathrm{K}_{\mathrm{B}}$ is Boltzmann constant and $\mathrm{E}_{\text {act }}$ is Activation Energy.

\section{Results and Discussion}

Fig.1 shows the variation of the dielectric constant of PVA-NaI composites with angular frequency. The figure shows that the dielectric constant values decrease when increasing the applied field frequencies. The increase of frequencies results in decreasing of space charge polarization to the total polarization. The space charge polarization becomes the more contributing type of polarization at low frequencies, and less contributing with the increase of frequency; this would result in the decrease of dielectric constant values for all samples of PVA-NaI composites with the increase of the electric field frequency $1 \mathrm{MHz}$.

The other types of polarizations appear at subsequent frequencies. The ionic polarization reacts slightly to the variation in the field frequencies compared to the electronic polarization. This is because the mass of ion is greater than that of the electron. The electrons respond to even the high frequencies of the field vibrations. The low mass of electron makes the electronic polarization the only type of polarization at higher frequencies. This makes the dielectric constant approximately constant for all samples at high frequencies $[9,10]$. 


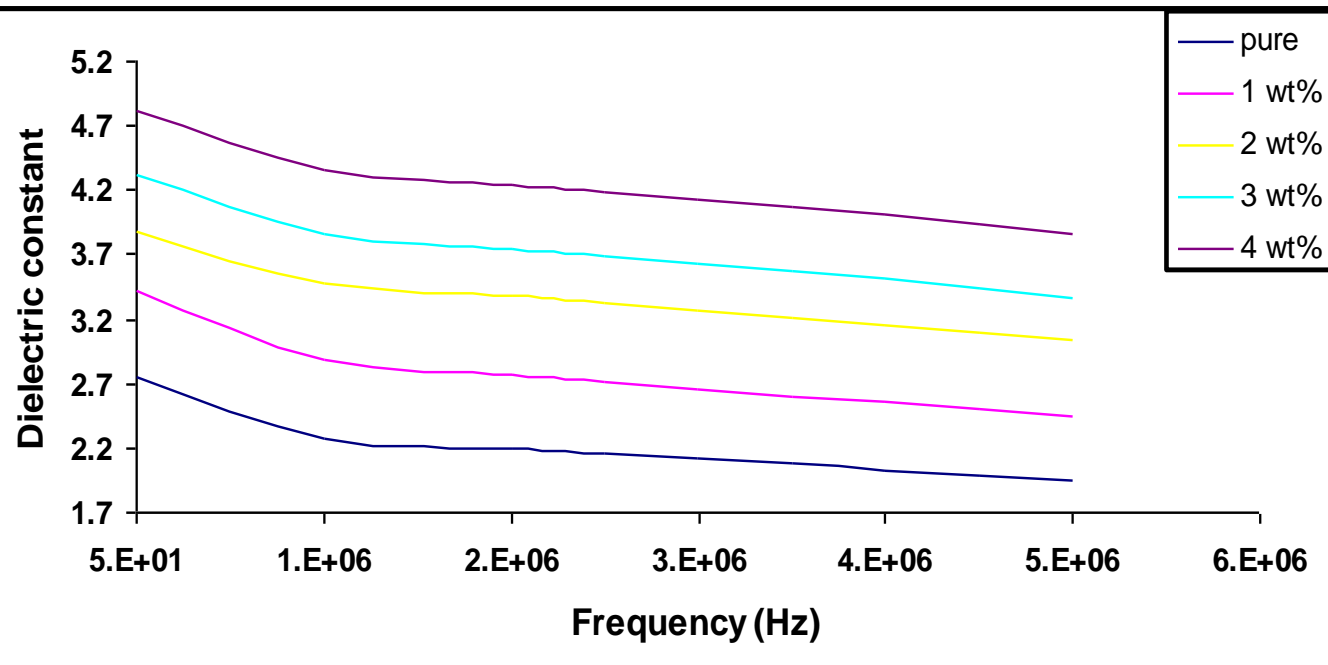

Fig.1 : The variation of the dielectric constant of (PVA-NaI) composites with angular frequency.

Fig. 2 shows the dielectric loss as a function of the angular frequency of PVA$\mathrm{NaI}$ composites. When the applied field frequency is low, the dielectric loss value is low, and it is increasing when increasing the frequency. The dielectric loss increases till it reaches to the highest value at $(1 \mathrm{MHz})$. This value represents the highest dielectric loss at certain frequency, which is the highest absorption of applied field. This absorption happens due to Maxwell- Wagner phenomenon which is caused by A.C current due to the difference of dielectric constant and conductivity of the phases in the composite. This electric current has the same phase as that of the applied field $[11,12]$.

When the frequency increase more than $1 \mathrm{MHz}$, the dielectric loss become constant. This is attributed to the mechanisms of other types of polarization that occurs at high frequencies. This is similar to the results reached by the researchers $[13,14]$.

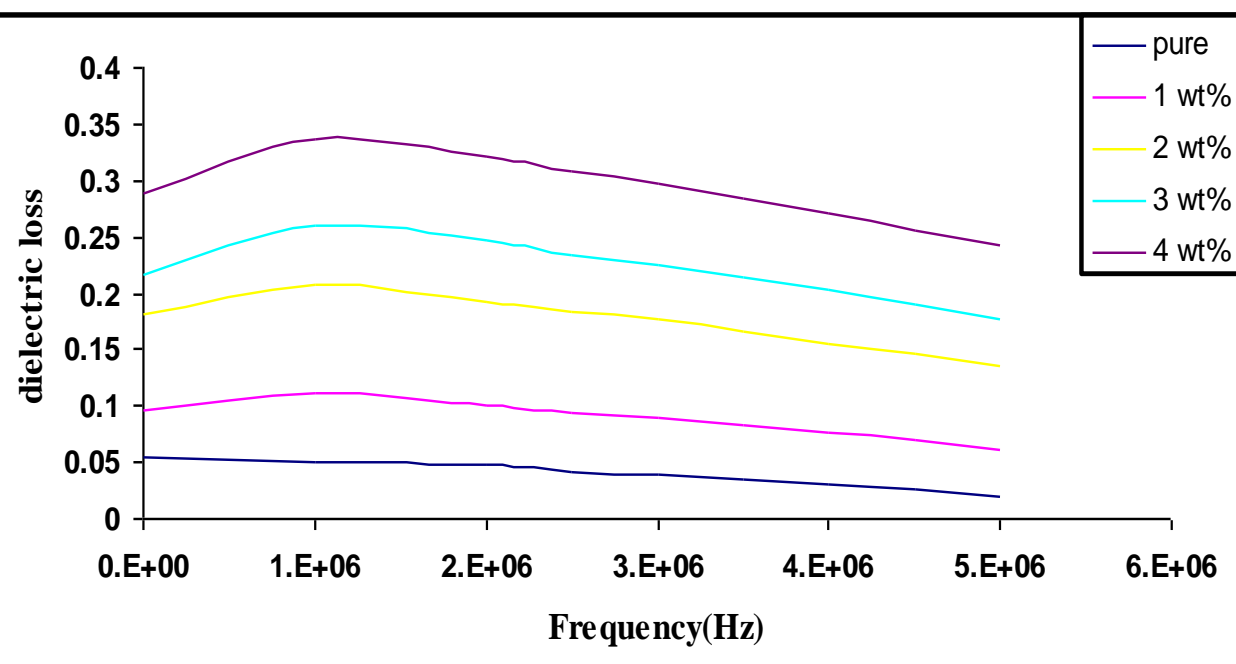

Fig.2 : Dielectric loss as a function of the angular frequency of PVA-NaI composites. 
Fig.3 shows the variation of the conductivity for PVA-NaI composites with angular frequency. The figures show that A.C conductivity increases considerably with the increase of frequency (f), this is attributed to the space charge polarization and also to the motion of charge carriers by hopping process [15], consequently, the is increasing when increasing the frequency and weight percentage of the NaI.

Fig.4 shows the variation of A.C conductivity of PVA-NaI composites, with sodium iodide wt $\%$ at $50 \mathrm{~Hz}$ and $298 \mathrm{k}$. The A.C conductivity is slightly increasing at low concentrations of the NaI. This increase is due to the effect of the space charge. The ions of sodium iodide take the form of clusters or separated groups. The conductivity increase with increasing of the wt\% of $\mathrm{NaI}$ as a result of the increase of the ionic charge carriers and the formation of a continuous network of $\mathrm{NaI}$ ions inside the composite. Consequently, the conductivity is increasing with the increasing of $\mathrm{NaI}$ wt\% $[16,17]$.

Fig.5 shows the electrical volume conductivity $\sigma_{\mathrm{v}}(\Omega . \mathrm{cm})^{-1}$ as a function of the wt $\%$ of sodium iodide $\mathrm{NaI}$ at $30^{\circ} \mathrm{C}$.

The increase of conductivity with increasing wt $\%$ of $\mathrm{NaI}$ caused by the increase of the charge carriers ions in which they increased with increasing filler content when the $\mathrm{NaI}$ ions at low wt\% and become large when the sodium iodide $\mathrm{NaI}$ content increases but when the concentration of $\mathrm{NaI}$ reaches to $3 \mathrm{wt} \%$, the network will be connected to each other containing the overlapping paths to allow the charge carriers to pass through, where the charge carriers with routes through which the electrical resistance be less [14].

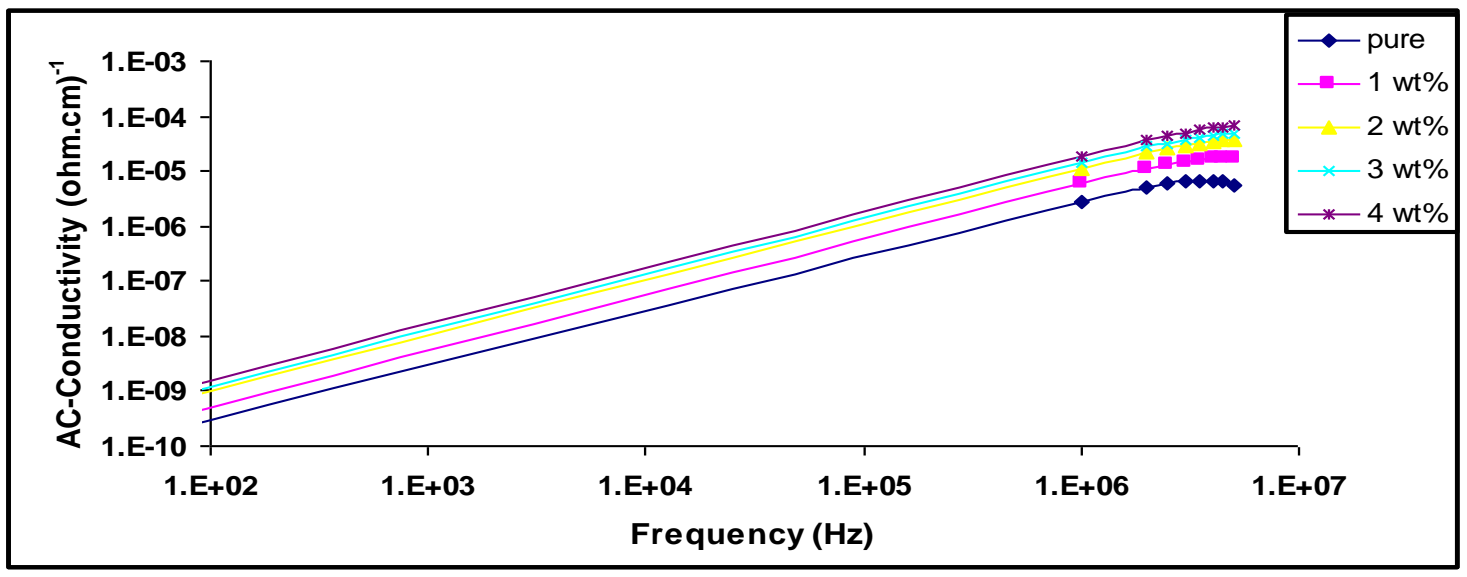

Fig.3 : AC conductivity for PVA- NaI composites with angular frequency.

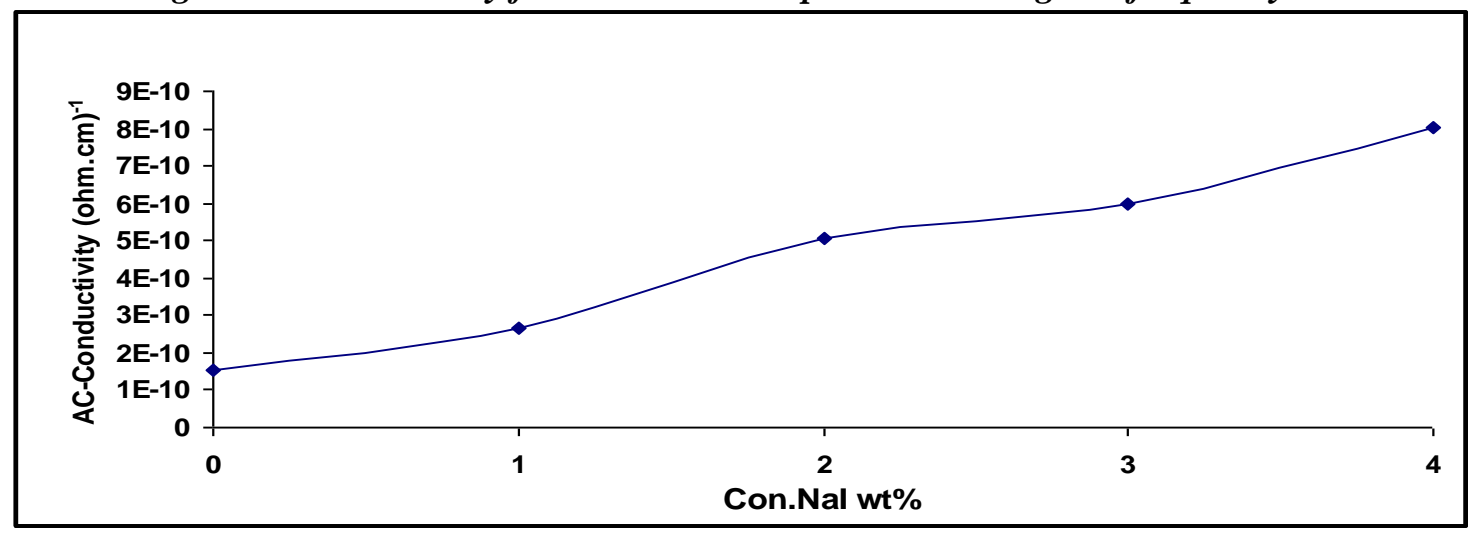

Fig.4 : A.C conductivity of PVA-NaI composites with sodium iodide concentration at $50 \mathrm{~Hz}$ and $298 \mathrm{~K}$. 


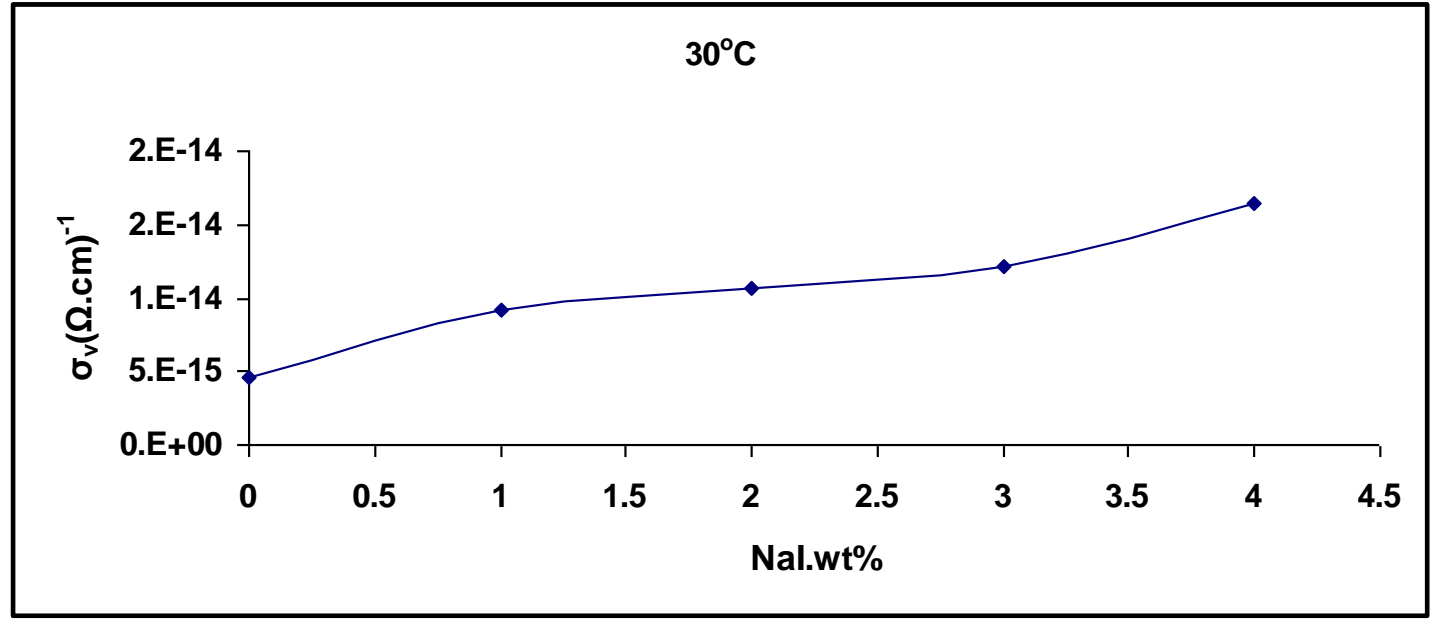

Fig.5:The electrical volume conductivity $\sigma_{v}(\Omega . c m)^{-1}$ as a function of the wt\% of sodium iodide NaI at a temperature $30^{\circ} \mathrm{C}$.

Fig.6 shows the relationship of electrical volume conductivity of the composite $\sigma_{\mathrm{v}}$ $(\Omega . \mathrm{cm})^{-1}$ with the temperature. We note that the electrical conductivity increases with increasing the temperature that any of this material has a positive thermal coefficient of conductivity, the interpretation of this is that the polymeric chains and $\mathrm{NaI}$ salts act as traps the charge carriers which transited by hopping process. On increasing the temperature, segments of the polymer being to move, releasing the trapped charges. The released of trapped charges is intimately associated with molecular motion. The increase of conductivity with temperature is attributed to two main parameters, charge carriers and mobility of these charges. The mobility depends on the structure and the temperature [18].

Fig. 7 shows the relation between $\ln \sigma_{v}$ and the inverse of absolute temperature for PVA-NaI Composites.

From these calculations, it can be seen that high activation energy occurs in the (0.28613-0.2152) eV.
By adding low wt\% of NaI, the values of the activation energy are decreasing as a result of the impact of space charge. The addition of low concentrations creates local energy levels in the forbidden energy gap which act as traps for charge carriers when move they among these levels.

By increasing the sodium iodide wt $\%$, the activation energy decreases as a result of the increase of local centers, as shown in Fig.8. Thus, the mechanism of conduction in the samples having low concentrations is the hopping.

The low values of the activation energy for PVA- NaI composites is $0.174 \mathrm{eV}$, this is attributed to the formation of a continuous network of sodium iodide that contains paths inside the composite and allows the charge carriers to pass through and this leads to decrease the activation energy. Increasing of the concentration of the additive, the activation energy decreases[18], as shown in the Fig.8. 


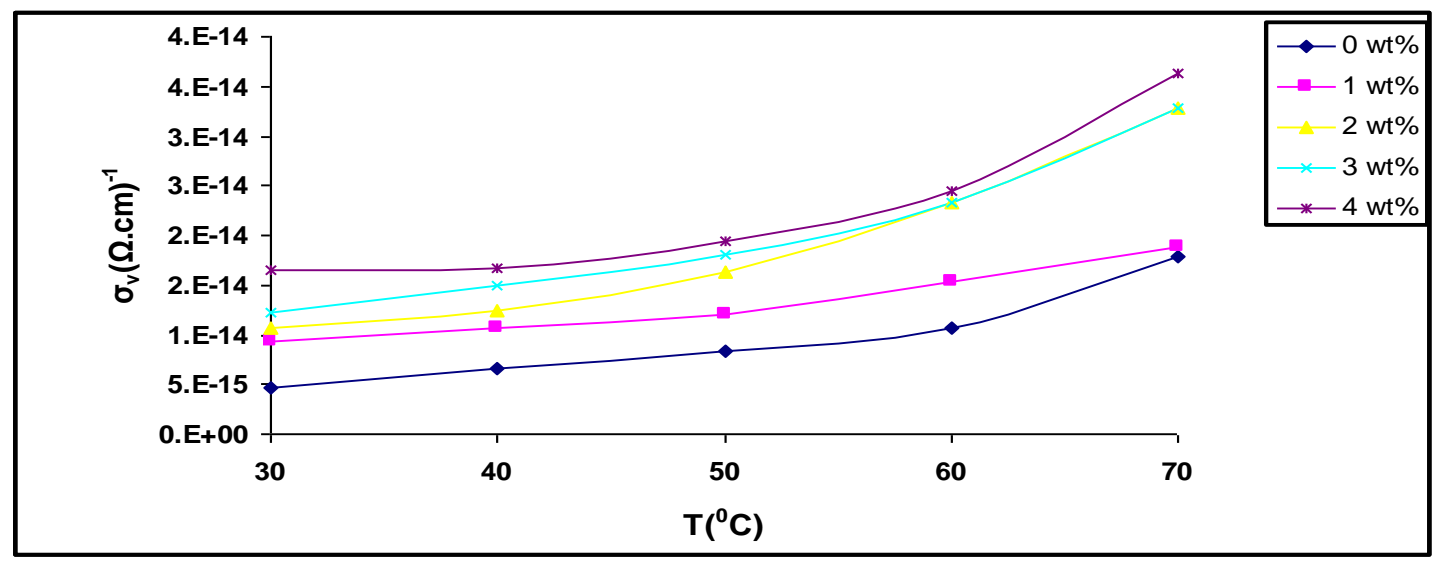

Fig.6 : Electrical volume conductivity of the composite $\sigma_{v}(\Omega . c m)^{-1}$ with the temperature.

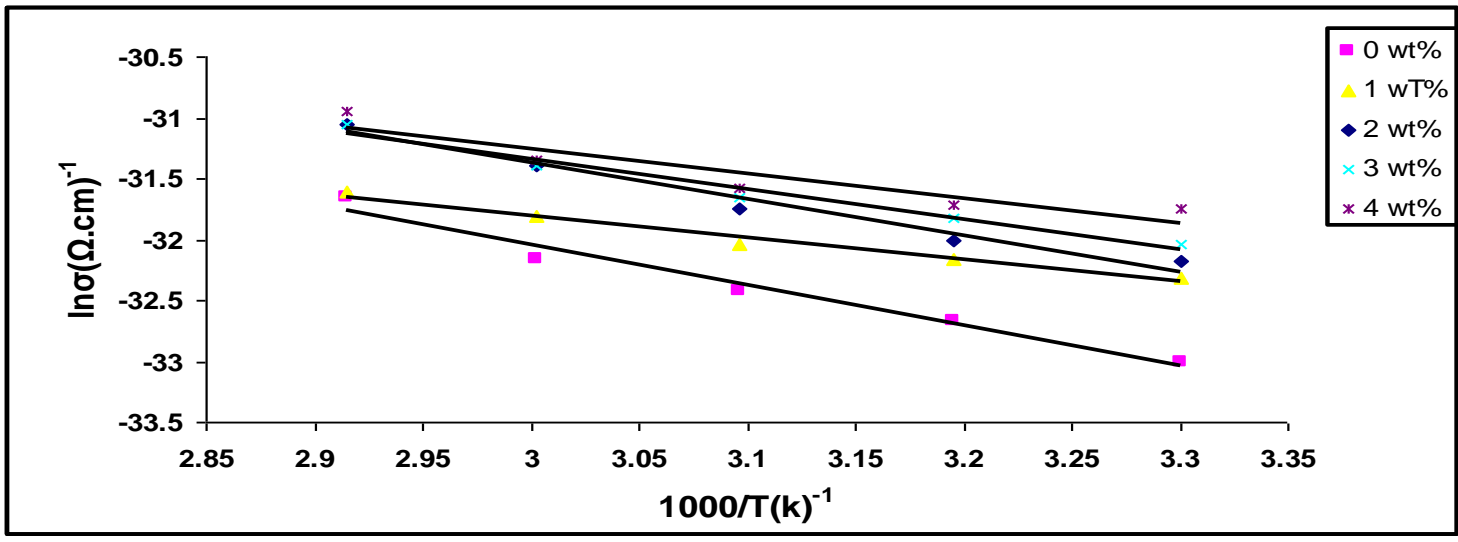

Fig. 7 : Electrical volume conductivity of the composite $\sigma_{v}(\Omega . c m)^{-1}$ with the temperature.

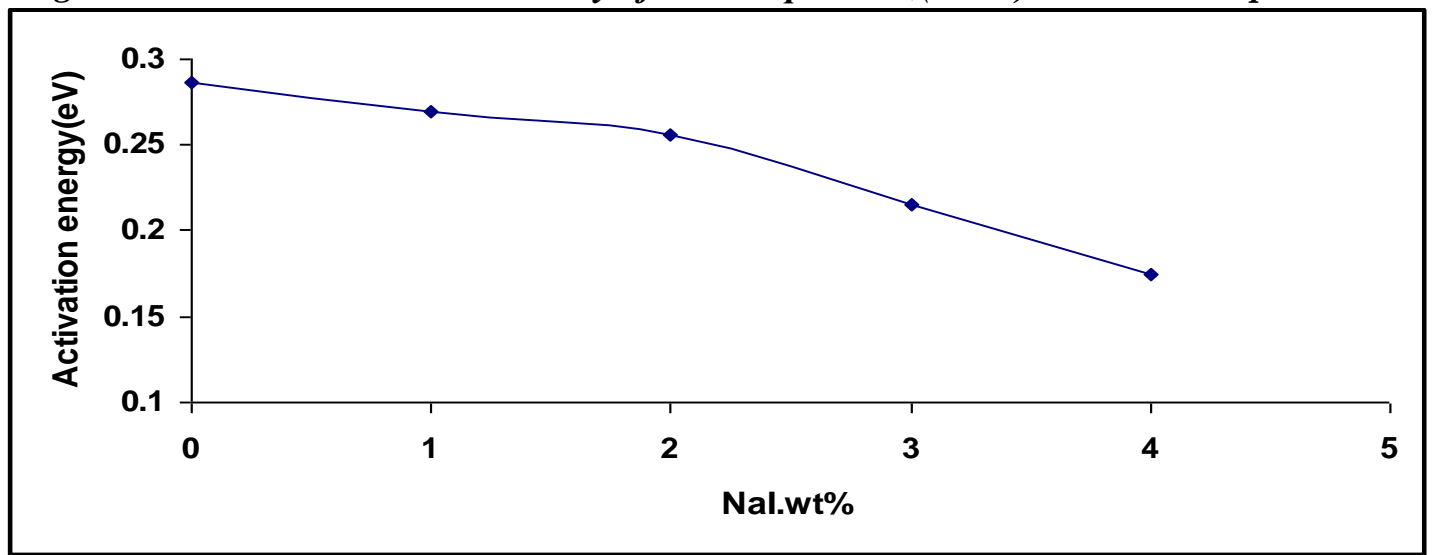

Fig.8: Activation energy and concentration of NaI wt\%.

\section{Conclusions}

1-The dielectric constant, dielectric loss, A.C electrical conductivity and the D.C electrical conductivity increase with increasing NaI.
2-The dielectric constant is decreasing with the increase of frequency of the applied electric field. 
3-The dielectric loss of low and high concentrations is oscillatory with the frequency of applied electric field.

4-The A.C electrical conductivity at all wt $\%$ is increase with increasing frequency of the applied electrical field.

5-The activation energy for D.C electrical conductivity are decreasing with increasing $\mathrm{NaI}$.

\section{References}

[1] T.G. Abdel-Malik, R.M. Abdel-Latif, A. Sawaby, and S.M. Ahmed, Journal of Applied Sciences Research, 4,3 (2008) 331336.

[2] M.Harun, E.Saion and A. Kassim, J. for the Advancement of Science, 1, 1 (2009) 916.

[3] T.Miyamoto and K.Shibayama, J. Appl. Phys., 44, 12 (1973) 5372.

[4] Z. Al-Ramadhan, J. of College of Education, Al-Mustansiriyah University, 3 (2008) 321-399

[5] H.Kuno and M.Senna, J. of Materials Science, Keio Uni., Japan, 12 (1977) 509516.

[6] A. Zaky and R. Hawley "Dielectric solid" Routlege and Kegan Paul Ltd, London, New York, 1970.

[7] R.A Levy "Principles of solid state physics", $4^{\text {th }}$ Ed, Academic press, 1970.

[8] W. Kingery "Introduction to Ceramics" John Wiley of Sons, Inc, NewYork, 1976. [9] C. Chiteme, S. Lowther and S. Harrison, J. of Polym. Science, 43 (2005) 3273-3287.
[10] M. Hamzah, E. Saion, A. Kassim, E. Mahmud and I. Shahrim, J. for the Advancement of Sci. 1, 1 (2009) 9-14.

[11] B. H Al-Khayat and F. A. Awni, J. Am. Ceram. Soc. Bull. 64,4 (1985) 598-601.

[12] M. Revanasiddappa, S.C. Raghavendra, S. Khasim and T. KVishnuvardhan, J. Bull. Korean Chem. Soc., 28, 7 (2007) 11041108.

[13] P. K. Pillal, P. Khurana and A. Tripathi, J. of Materials Sci. Letters, 5 (1986) 629632.

[14] S. Satapathy, P. K. Gupta, K. B. R. Varma, P. Tiwari and V. Ganeshan, "Study on dielectric behavior of Lithium Tantalate (LT) nano particl filled poly (vinylidene fluoride) (PVDF) nano composites", Institute of Science, India, 2008.

[15] T. K. Vishnuvardhan, V. R. Kulkarni, C. Basavaraja and S.C. Raghavendra, J. Bull. Mater. Sci., 29, 1 (2006) 77-83.

[16] G. Shui, J. Hu, M. Qiu, M. Wei and D. Xiao, J. Chinese Chem. Letters, 15, 12 (2004) 1501-1504.

[17] M. P. Alvarez, V. H. Poblete, M. E. Pilleux and V. M. Fuenzalida, "Submicron Copper- Low- Density polyethylene conducting composites: Structural, Electrical and percolation Threshold", Comision Chilena de Energia Nuclear, Chile, 2008.

[18] K. M. Gabur, "Preparation and Study The Electrical and Optical Properties of (PSNi) Composites", M.Sc. Thesis, Babylon University, College of Science, 2010. 